\title{
Simulation of Metal Additive Manufacturing
}

\author{
J. Angel Diosdado De la Pena, Kyosung Choo' \\ ${ }^{1}$ Mechanical Engineering, \\ Youngstown State University, Youngstown, OH 44555, United States \\ kchoo@ysu.edu
}

\section{Extended Abstract}

Metal additive manufacturing (MAM) has gained interest due to its capability to produce metallic components with complex geometry by depositing consecutives layers of material that will shape said geometry through Direct Energy Deposition (DED) [1-3]. DED processes employ a high energy source, commonly a laser, to melt and laid metals [4]. Different DED technologies are commercially available such as Laser cladding (LC), Direct metal deposition (DMD), Laser engineer net shaping (LENS), Laser powder fusion (LPF), to name a few; these have been used to process various titanium, steel, nickel and aluminium alloys, among others [5]. It has been identified that DED processes are mainly influenced by the heat source power, scanning speed, feeding rate, and scanning strategy, and the exploration of these parameters with numerical simulation reduces experimental efforts [5, 6]. Numerical modeling by using finite element method (FEM) software has been used to explore the effect of the process parameters in the temperature distribution, either heating, cooling or both, as well as residual stresses, residual deformation and grain formation; commercial and selfdeveloped code was reported in literature with good agreement to reference data [2, 6-12]. FEM cases are also employed to validate new methods such as the modified inherent strain method and the invasion model in MAM [1, 13], as well as to evaluate diverse heat source models applicable to laser heating [14]. Based on this, a thermal-transient model in ANSYS® is proposed to reproduce a reference case [15]. The model considers a single-straight wall $(12.6 \times 38.1 \mathrm{~mm} \times 3.0 \mathrm{~mm}) \mathrm{on}$ a rectangular substrate $(6.35 \mathrm{~mm} \times 76.2 \mathrm{~mm} \times 38.1 \mathrm{~mm})$. The geometry is meshed with 20-nodes hexahedral elements, limited to a minimum element size of $0.75 \mathrm{~mm}$ but forced to 62 divisions for the wall height. Sets of elements in each layer were created independently to allow for element birth/death commands and each set would be deposited as the heat source scans the geometry. A moving heating source is defined and travels at $8.47 \mathrm{~mm} / \mathrm{s}$, heating the top surface of the deposited elements; the parameters of the heat source were fitted to a laser with power of $425 \mathrm{~W}, 1.5 \mathrm{~mm}$ beam radius and process efficiency of 0.45 . The initial temperature of the wall and substrate geometries and the surrounding temperature are defined as $30.5^{\circ} \mathrm{C}$. Free convection boundary condition is assumed on every surface of the model and set to $10 \mathrm{~W} / \mathrm{mm}^{2} /{ }^{\circ} \mathrm{C}$. Wall and substrate are both assumed as Ti-6Al-4V with temperature dependent material properties [1-3, 15]. The proposed model agrees qualitatively with the reference case for the temperature profile from the first deposited layer down to the bottom of the substrate. Nonetheless, there are some significant differences quantitatively, while temperature at the surface and almost $0.1 \mathrm{~mm}$ below are only $5 \%$ different that the reference case and at the substrate bottom around $10 \%$, the temperature in the midsection decreases rapidly and around $2.4 \mathrm{~mm}$ below the first layer the temperature difference is almost 50\%. These results indicate that the proposed model behaves as expected, but improvements are required on the boundary condition and the heat source definition perhaps.

\section{References}

[1] X. Liang, L. Cheng, Q. Chen, Q. Yang, and A. C. To, "A modified method for estimating inherent strains from detailed process simulation for fast residual distortion prediction of single-walled structures fabricated by directed energy deposition," Addit. Manuf., vol. 23, no. July, pp. 471-486, 2018, doi: 10.1016/j.addma.2018.08.029.

[2] J. C. Heigel, P. Michaleris, and E. W. Reutzel, "Thermo-mechanical model development and validation of directed energy deposition additive manufacturing of Ti-6Al-4V," Addit. Manuf., vol. 5, pp. 9-19, 2015, doi: 10.1016/j.addma.2014.10.003.

[3] Q. Wang, J. Li, M. Gouge, A. R. Nassar, P. Michaleris, and E. W. Reutzel, "Reduced-order multivariable modeling and nonlinear control of melt-pool geometry and temperature in directed energy deposition," in Proceedings of the American Control Conference, 2016, pp. 845-851, doi: 10.1109/ACC.2016.7525019. 
[4] J. Mazumder and L. Song, "Advances in Direct Metal Deposition," in Proceedings of the ASME 2013 International Mechanical Engineering Congress and Exposition, 2013, pp. 1-6.

[5] A. Saboori, D. Gallo, S. Biamino, P. Fino, and M. Lombardi, "An overview of additive manufacturing of titanium components by directed energy deposition: Microstructure and mechanical properties," Appl. Sci., vol. 7, no. 9, 2017, doi: 10.3390/app7090883.

[6] M. Biegler, A. Marko, B. Graf, and M. Rethmeier, "Finite element analysis of in-situ distortion and bulging for an arbitrarily curved additive manufacturing directed energy deposition geometry," Addit. Manuf., vol. 24, no. September, pp. 264-272, 2018, doi: 10.1016/j.addma.2018.10.006.

[7] S. ZEKOVIC, R. DWIVEDI, and R. KOVACEVIC, "Thermo-structural Finite Element Analysis of Direct Laser Metal Deposited Thin-Walled Structures," in Solid Freeform Fabrication 2005, 2005, vol. 42, no. 1, pp. 665-700.

[8] G. Marion, G. Cailletaud, C. Colin, and M. Mazière, "A finite element model for the simulation of pile driving," in International Congress on Applications of Lasers \& Electro-Optics, 2014, vol. 2014, no. 1, pp. 834-841, doi: https://doi.org/10.2351/1.5063133.

[9] Q. Yang, P. Zhang, L. Cheng, Z. Min, M. Chyu, and A. C. To, "Finite element modeling and validation of thermomechanical behavior of Ti-6Al-4V in directed energy deposition additive manufacturing," Addit. Manuf., vol. 12, pp. 169-177, 2016, doi: 10.1016/j.addma.2016.06.012.

[10] M. E. Stender, L. L. Beghini, J. D Sugar, M. G. Veilleux, S. R. Subia, T. R. Smith, C. W. S. Marchi, A. A. Brown, D. J. Dagel, "A thermal-mechanical finite element workflow for directed energy deposition additive manufacturing process modeling," Addit. Manuf., vol. 21, no. April, pp. 556-566, 2018, doi: 10.1016/j.addma.2018.04.012.

[11] B. L. Chua, H. J. Lee, D. G. Ahn, and J. G. Kim, "Influence of process parameters on temperature and residual stress distributions of the deposited part by a Ti-6Al-4V wire feeding type direct energy deposition process," J. Mech. Sci. Technol., vol. 32, no. 11, pp. 5363-5372, 2018, doi: 10.1007/s12206-018-1035-6.

[12] T. Amine, J. W. Newkirk, and F. Liou, "An investigation of the effect of direct metal deposition parameters on the characteristics of the deposited layers," Case Stud. Therm. Eng., vol. 3, pp. 21-34, 2014, doi: 10.1016/j.csite.2014.02.002.

[13] J. Li, Z. Luo, X. Guan, X. Zhou, M. Brochu, and Y. F. Zhao, "A Novel Microstructure Simulation Model for Direct Energy Deposition Process," in Solid Freeform Fabrication 2018, 2018, pp. 1737-1750.

[14] T. Kik, "Heat source models in numerical simulations of laser welding," Materials (Basel)., vol. 13, no. 11, pp. 1-25, 2020, doi: 10.3390/ma13112653.

[15] P. Michaleris, "Modeling metal deposition in heat transfer analyses of additive manufacturing processes," Finite Elem. Anal. Des., vol. 86, pp. 51-60, 2014, doi: 10.1016/j.finel.2014.04.003. 